\title{
HUMANISMO TECNOCIENTÍFICO E METAFÍSICA REALIZADA
}

\author{
Antônio José Nascimento ${ }^{1}$ \\ Universidade Federal de Sergipe (UFS) \\ (iD) https://orcid.org/0000-0002-6970-0617 \\ E-mail: ajntoinho@outlook.com
}

\section{RESUMO:}

A cabal organização técnica do mundo corresponde à era da metafísica consumada -como a viu Heidegger, mas não Habermas- e à instrumentalização do pensamento que automatiza a existência humana, tornando-a inteiramente dependente do cálculo que move a disponibilização de tudo em conformidade com a vontade de poder da "armação" (Gestell). A tecnificação da vida, com os constrangimentos que derivam da rigidez de sua própria lógica, não se apresenta como mero produto ou desdobramento de necessidades naturais do humano tornado "sujeito" da técnica. A esse respeito, a metafísica do humanismo -e seu braço operativo, a ciência moderna enquanto tecnociênciaconsiste na antropologia da determinação técnica do mundo pela volição humana.

PAlaVRaS-CHAVE: Técnica; Metafísica; 'Vontade de Poder'; Humanismo; Ciência.

\section{TECHNOSCIENTIFIC HUMANISM AND ACCOMPPLISHED METAPHYSICS}

\begin{abstract}
:
The thorough technical organization of the world corresponds to the age of consummate metaphysics -as Heidegger, but not Habermas, saw it- and to the instrumentalization of thought that automates human existence, making it entirely dependent on the calculus that moves the availability of everything in accordance with the will to power of the "inframing" (Gestell).The technification of life, with the constraints that derive from the rigidity of its own logic, is not a mere product or unfolding of the natural needs of the human made "subject" of technique. In this respect, the metaphysics of humanism - and its operative arm, modern science as technoscience- consists in the anthropology of the technical determination of the world by human volition.
\end{abstract}

KEYWORDS: Technique; Metaphysics; 'Will to Power'; Humanism, Science.

\footnotetext{
1 Doutor em Filosofia pela Universidade de Évora (UÉVORA), Portugal. Professor da Universidade Federal de
} Sergipe (UFS), São Cristóvão - SE, Brasil.

NASCIMENTO, Antônio José. Humanismo tecnocientífico e metafísica realizada. Griot : Revista de Filosofia, Amargosa - BA, v.20, n.2, p.129-139, junho, 2020. 


\section{Introdução}

A tecnologia é o que define nosso "modo de ser" contemporâneo, na medida em que confere à existência humana um sentido vinculado unicamente ao modus técnico de desvelar o mundo como provocação. Entretanto, em si mesmo esse desvelamento não constitui um poder do homem, visto que não se trata apenas de um meio. Nas palavras de Heidegger (2012a, p. 28), o império da armação tecnológica é "a fatalidade de nossa época", o destino histórico de uma forma de interpelação produtora que acaba por submeter o homem e a vida em geral ao ordenamento do cálculo estruturante de toda realidade, na qual o ser é subsumido na função e a verdade, na operatividade.

A técnica, pois, não é mera natureza dominada, um utensílio qualquer e muito menos a prática de manuseio dessa ou daquela ferramenta, como é comum à abordagem instrumental ou antropológica. Tampouco é mera conversão das ciências exatas da natureza, popularizada na fórmula segundo a qual a tecnologia é tão-somente conhecimento aplicado, que assumiu caráter de prestabilidade na forma de provimento, pela atividade de produção, de mais e melhores bens e serviços propiciadores de bem-estar. Embora, como expressão do projeto da modernidade, a técnica corresponda a tudo isso aí como precedência das práxis, por outro lado há que se ter em conta, sobretudo, sua dimensão essencial como pura vontade de poder, como força cega e trágica que se quer a si mesma para cumprir-se como destinação da abertura ao desmesurável no autoengrandecimento.

É em meio a esse conjunto de coisas que o presente artigo desenvolve, inicialmente, algumas reflexões acerca da modernidade e do pensamento pós-metafísico em Habermas, para, a partir disso, situar, à guisa de contraponto, o posicionamento de Heidegger no tocante ao acabamento da metafísica, ao humanismo e à ciência na era da "vontade de vontade" da técnica.

\section{Modernidade e pensamento pós-metafísico em Habermas}

Segundo Habermas (2000), a modernidade compreende um processo de desenvolvimento histórico que assomou na Europa a partir, grosso modo, do séc. XV (com o Novo Mundo, o Renascimento, a Reforma etc), num continuum que resultaria no espírito científico, na Ilustração e emancipação do indivíduo, bem como naquilo que Weber assinalaria como dessacralização, desencantamento do mundo, abandono de valores tradicionais, crescente impessoalização burocrática proveniente da emergência dos estados nacionais e, sobretudo, a racionalização com respeito a fins.

Numa altura em que a Filosofia se debatia com a "tarefa de elaborar o conteúdo de seu tempo" (HABERMAS, 2000, p.25), Hegel, antes mesmo de Weber, já o tomava por moderno. Foi, assim, o primeiro filósofo a elaborar um conceito de modernidade, e o fez vinculando os novos tempos à ideia de movimento. $\mathrm{O}$ repertório de expressões e categorias que elegeu para isso não deixa dúvida: "revolução, progresso, emancipação, desenvolvimento, crise, espírito do tempo etc" (HABERMAS, 2000, p.12). Ainda de acordo com Habermas, o mérito de Hegel, ao notar como a modernidade sem modelo engendrava sua própria normatividade, foi ter descoberto a subjetividade como princípio dos novos tempos. E é sob os auspícios, aqui, de uma filosofia da consciência que Habermas aglutina a pluralidade das teorias metafísicas de Platão a Hegel.

A seu ver, a desvalorização final da metafísica e os aspectos que marcaram seu estremecimento e subsequente passagem ao pensamento pós-metafísico se deveram, num primeiro instante, ao solapamento mesmo do pensamento totalizador suscitado pelo experimentalismo das ciências modernas. A isso se somou o aparecimento das ciências histórico-hermenêuticas, que 
acabaram por se constituir, por sua relação com a temporalidade, a contingência e a consciência histórica, numa oposição à razão não situada. Outro fator teria sido a mudança de paradigmas da filosofia da consciência para a filosofia da linguagem, como desdobramento das críticas aos fundamentos da filosofia centrada no exclusivismo da relação sujeito-objeto; e, por último, mas não menos importante, o desfalecimento do primado da teoria frente às práxis, em virtude da pragmática dos novos contextos de formação e de inserção teórica (Cf. HABERMAS, 1990, p.43).

Em conjunto, essas circunstâncias determinaram, no entender de Habermas, o colapso do pensamento metafísico. Explica-se: as estruturas da razão esclarecedora já não estariam mais aptas a edificar uma totalidade do mundo, o que significa dizer que a razão cognoscente, com sua fundamentação transcendental, não logra mais conferir ao mundo ou à história um conteúdo que faça sentido do ponto de vista de uma constituição ou estruturação racionalizada do todo. Pretender que assim o fosse implicaria manter a Filosofia no âmago da metafísica. Mas sucede que tal não é mais possível, porque com a emergência das ciências experimentais modernas, que passaram a confiar unicamente na racionalidade de seu próprio procedimento, a razão se viu reduzida, para Habermas, ao aspecto formal, com o que a racionalidade dos conteúdos cai dependente da racionalidade procedimental voltada à resolução de problemas. Assim,

\begin{abstract}
a validade dos conteúdos volatiliza-se na validade dos resultados. Passa a valer como racional não mais a ordem das coisas encontrada no próprio mundo ou concebida pelo sujeito, nem aquela surgida do processo de formação do espírito, mas somente a solução de problemas que aparecem no momento em que se manipula a realidade de modo metodicamente correto (HABERMAS, 1990, p.44).
\end{abstract}

À luz disso, pode-se entrever a que estado de coisas estão condenadas as ciências ditas hermenêuticas. A objetivação da natureza, a cargo das ciências empíricas, consolidou-se de uma vez por todas como o modelo por excelência da cientificidade. Como resultado, as ciências hermenêuticas e suas pautas exegéticas acabaram relegadas, conforme Habermas (1990, p.45)

ao mundo histórico-cultural através do enfoque performativo [...] um conhecimento de essências que, explicitador de contextos de sentido, ricocheteia numa natureza objetivada [...] naquela esfera do não-ente, na qual, entretanto, de acordo com a compreensão metafísica, as essências ideais jamais devem fincar pé!.

A tais considerações Habermas emenda outras tantas a respeito, agora, do subterfúgio da Filosofia em sua guinada em direção ao irracional, em que diz o seguinte:

Ela' (a Filosofia, no caso) 'apresentou-se como fé filosófica e iluminação da existência em (Jaspers), como mito complementador das ciências (Kolakowski), como pensamento místico do ser (Heidegger), como tratamento terapêutico da linguagem (Wittgenstein), como atividade desconstrutiva (Derrida) ou como dialética negativa (Adorno) [HABERMAS, 1990, p.47].

Sua conclusão é a de que, nessas circunstâncias assaz embaraçosas para a Filosofia, faz-se necessário determinar um novo nexo entre ela e a ciência, posto que, não sendo mais a Filosofia a ciência primeira, não pode mais, por conseguinte, garantir seu status quer pela via da assimilação às ciências particulares, quer pela da exclusividade distanciadora em relação às ciências. Como que divisando uma espécie de terceira via, postula que

ela precisa travar relações com a autocompreensão falibilista e com a racionalidade metódica das ciências experimentais; ela não pode pretender 
um acesso privilegiado à verdade, nem um método próprio ou um campo de objetos próprio, nem mesmo um estilo próprio de intuição (HABERMAS, 1990, p.47).

Mas, de tudo o que foi dito, nada, conforme nosso entendimento aqui, tem mais peso determinativo para o ocaso do pensamento metafísico que a falência do que Habermas enxergou como precedência clássica da teoria frente à prática, que se veio registrando no curso de um processo complexo, mas progressivo de exaurimento da razão autorreferida. Segundo ele, "todas as formas modernas de ceticismo se alimentam preferentemente dessa fonte" (HABERMAS, 1990, p.48). Com efeito, não se pode negar que essa falência do primado da teoria constitui, sem mais, um claro sintoma do desfalecimento da subjetividade, e como tal da própria crise do humanismo. Mas isso não deveria significar, como não significa em Heidegger -a exemplo de como se configura em Habermas-, que o homem devesse entregar-se, plenamente e sem reservas, aos imperativos da técnica, em sua destinação concernente ao modo de o humano tornar manifesta a realidade como presentificação injuntiva do mundo.

Enfim, à Filosofia restaria, para Habermas, o consolo da "instância crítica", já que não está mais na posse de uma teoria afirmativa da vida concreta. É nesse horizonte, como portadora da crítica, que a filosofia pode vir a desempenhar seu papel de intérprete na mediação "entre o saber dos experts e a prática cotidiana necessitada de orientação" (HABERMAS, 1990, p.60). A partir daí, quando muito, poderá a Filosofia colocar a descoberto "o sentido subjacente na formação científica das teorias -opondo-se à fundamentação última, metafísica, do saber em geral" (HABERMAS, 1990, p.58).

\section{Heidegger e o acabamento da Metafísica}

Desde logo, o "pensar" da técnica em Heidegger, enquanto "pensar" unilateral, não corresponde propriamente a um pensamento, mas a uma muito redutora, e por isso mesmo simplória, modalidade do pensar-operatório e calculista, isto é, a uma maneira de conduzir, a um fazer-aparecer radicado na manipulação da essência das coisas, porque o importante, no caso, não é a reflexão, mas o resultado antevisto na segurança do cálculo objetificante do projeto, que é uma forma claramente apriorística de dominação e controle do ente em sua totalidade. Em Nietzsche $(2007,2011)$, isso se traduz por desertificação do pensamento, e em Arendt (1964, p.122) assoma no que disse a propósito da "personalidade passiva" de Eichmann enquanto hosti humani generis cumpridor de ordens burocráticas, um autômato da execução sem pensamento, um operador acrítico de determinações técnicas que não lhe pareciam concernir como pessoa humana, e que, por isto mesmo, supôs não lhe cabe interpelá-las. Apenas executá-las, sem dramas de consciência.

De saída, pois, não há como se possa aceitar de todo que a metafísica desapareceu do horizonte da tecnociência -apenas para usar um termo, digamos, mais afeito à precedência que Heidegger reivindicou para a essência da técnica na constituição da ciência moderna, dado, aqui, seu a priori tecnológico como expressão da objetivação da vida e da quantificação da natureza. Em Habermas, por sua vez, conquanto se possa vincular o fenômeno tecnológico ao cariz da racionalidade estratégica ou instrumental, o fato, contudo, é que a tecnociência, como tal, não se reveste para ele de uma problematicidade. Quando muito, parecer-lhe-ia corresponder melhor àquilo que se entende por uma aliança convencional ciência-técnica com vistas ao desenvolvimento das forças produtivas e à "organização tecnicamente necessária de uma sociedade racionalizada" (HABERMAS, 1986, pp. 56-57). 
Heidegger, ao contrário, conferiu à ciência e à técnica um caráter específico de nossa forma de estar no mundo -não, por certo, num mundo-ambiente, mas no "sem-mundo" do meioambiente da natureza dessubstancializada, e por isso mesmo explorada como existente-coisa a serviço do incondicionado da subjetividade instada pela vontade de poder da técnica. Nesse sentido, a técnica é muito mais marcante, como "questão", para o próprio Heidegger-por motivos óbvios. A começar pelo fato de que, como bem lembrou Leopoldo e Silva (2007, p.369), ao colocá-la em "questão" Heidegger "antecipadamente elimina algumas possibilidades, tais como Investigação e Definição", porquanto não se trata aí de tomá-la como objeto específico de investigação conduzida com o intuito de fazer sobressair algo como uma tipificação da tecnologia ou mesmo articular sua definição como subsidiária de um processo de conhecimento. Vale dizer:

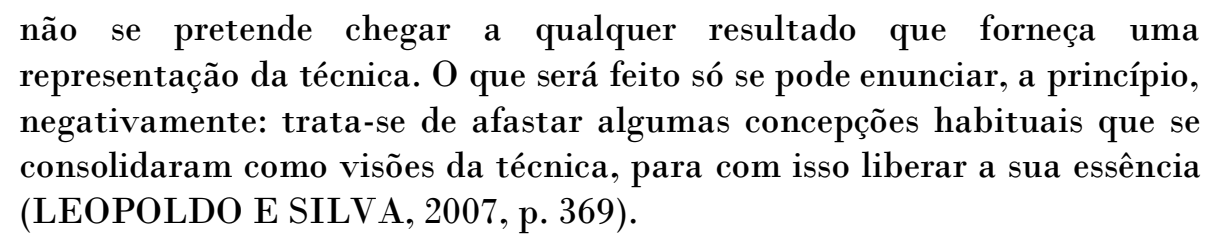

No que tange, então, à questão do "pensamento pós-metafísico", ali onde algum paralelo entre ambos os autores se afigura à primeira vista aproximativo, por razões de terminologia, convém guardar que o Heidegger d'A Superação da Metafísica (2012b) não tem propriamente que ver, nos pormenores cruciais dessa matéria, com o Habermas d'O Pensamento Pós-Metafísico (1990). Quando fala em superação, Heidegger dá indicações de que não está, com isso, de modo algum se referindo a um pensamento superado, por mais plausível que pareça o diagnóstico de que a situação geral das coisas aponte para um esgotamento do pensamento da totalidade.

Mesmo que se pudesse dar por superada a metafísica, ainda assim, segundo Heidegger, não se poderia falar, peremptoriamente, em superação. É que "depois de superada" -disse ele-“"a metafísica não desaparece. Retorna transformada e permanece no poder como a diferença ainda vigente entre ser e ente" (HEIDEGGER, 2012b, p.62). Superação, nessas circunstâncias, não guarda relação alguma com o fenômeno do progresso que é característico da vida moderna; não tem nada que ver com o movimento de precipitação do envelhecimento das coisas e sua substituição pelo novo que é, desde logo, um ultrapassamento, uma forma de superação do existente tornado anacrônico.

Bem entendida, a superação da metafísica em Heidegger prenuncia-se como uma Verwindung que conduz a um "sobrepor-se do esquecimento do ser" (ibid., p.60), e não já como um fim em si do pensamento metafísico remetido a qualquer coisa como cessação de sua vigência ou sua definitiva superação, mas antes sua consumação, no sentido de algo que se encaminha rumo ao seu próprio acabamento, à sua máxima expressão

Como bem lembrou Vattimo (1980, pp.13-14), não constitui tarefa trivial o desvencilharse de uma tradição como a da metafísica, que é a do "pensamento violento" (unificador, soberano, generalizante etc.) enquanto estrutura fixa e fundamental do Ser, quer dizer, enquanto "figura sem verdade" (PICOTTI, 2010, p.56) da realidade do real do ente impossibilitado de acontecer como autodeterminação, como princípio da realidade de seu ser. Em seu desdobramento histórico, o projeto oculto da metafísica (o do ser da ontologia convencional como fundamento) cumpre-se como influxo mobilizador do que não pode ser evitado ou preterido. Não é como o que sucede com uma opinião desfeita ou mesmo com uma doutrina na qual deixamos de acreditar (Cf. PICOTTI, 2020, p.61). Segundo Sánchez Meca (2010, p. 15), 
[...] a metafísica, como esquecimento do ser, se desenvolve e realiza finalmente suas próprias pretensões na modernidade, onde não se produz propriamente uma superação da metafísica pelo desenvolvimento do conhecimento científico, senão que é através desse desenvolvimento que se reafirma e se realiza finalmente o projeto originário da metafísica.

Noutras palavras, a técnica é o apanágio da época na qual se cumpre plenamente a metafísica ocidental imposta à escala planetária (Cf. BORGES-DUARTE, 2014, p.172). Daí a interdição do questionamento acerca do ser, seu esquecimento e por fim o esquecimento desse esquecimento que acompanha o domínio incondicional do ente nesse momento de ordenação histórica da completação da metafísica.

Ao contrário, portanto, de uma ruptura com essa "história" - a da metafísica e suas determinações-, sucede justamente o oposto, isto é, o aprofundamento de sua vigência, robustecida por meio do predomínio do entendimento da constância da entidade -discernível e mostrável- dos entes como seu fundamento último. Basicamente, tratou-se da consolidação, na era da técnica, de uma linhagem do pensamento que nos constitui, enquanto destinação e fatalidade, sob o signo dessa historicidade mesma do ser entendido como explicitação de um fundamento ideacional dos entes.

Por fatalidade, aí, entenda-se o inexorável num engajamento, numa condição de possibilidade que estrutura e plasma o pensamento ocidental como perspectiva para descortinar o processo histórico de asseguramento da humanidade no ente, isto é, no domínio do ente como negação da verdade do ser ou como esquecimento do ser que se dá em chave com a metafísica realizada na era da tecnificação planetária.

Ao reportar-se, num primeiro instante, à Destruktion da metafísica e, mais adiante, na pós-Kehre, à sua "superação" ou "acabamento", Heidegger (2012b, p.67) pretendeu com isso, segundo Arendt (2000, p.190), "voltar-se contra a autoafirmação do homem" e sua característica vontade de poder que é própria da subjetivação da era moderna. Dessa forma, abalou o próprio fundamento metafísico do humanismo moderno, quando deu à ideia de fim ou acabamento da metafísica a conotação de sua culminância na técnica globalizada e englobante, cujo poderio não se resume apenas ao domínio per se do âmbito operatório e das virtualidades dos processamentos mecânicos, porquanto constitui já, decisivamente, uma transformação em nossa existência, em nosso modo de pensar, de ver o mundo e de sistematizar a vida.

A isso, como se sabe, Heidegger (2012d, p.124) opôs um "pensar que não é um querer" como o da Gelassenheit (Serenidade) -, que corresponde a um "deixar-ser" preparatório de um gênero novo de residir na proximidade das coisas, ao qual já não corresponderia mais a maneira preponderante de se forjar o aparecimento dos entes que é própria da época da técnica, abrigada na "representatividade" de tudo como fabricável.

Mas dado que não se verificou ainda uma superação efetiva das injunções da metafísica, pelo fato de o homem não ter podido voltar a pensar livremente o ser, tal não significa, entretanto, o definitivo arresto do humano ao poder global da técnica, isto é, conquanto, de fato, avassalador, o poder planetário da técnica -desencadeado pela metafísica-,não nos deveria necessariamente trancar em sua coação obtusa, forçando-nos a uma entrega cega à eficácia do modo de funcionamento da técnica, que é em tudo impeditivo de uma relação do homem com o ser.

Por outro lado, tampouco deveria implicar num arremetimento alucinado contra ela, a fim de poder condená-la, sem mais, como obra mefistofélica, mesmo porque não está ao alcance do homem o controle do destino do ser, e, portanto, dos meios através dos quais pudesse orquestrar o fim da dominação técnica. "Ao contrário, abrindo-nos para a essência da técnica, 
encontramo-nos, de repente, tomados por um apelo de libertação" (HEIDEGGER, 2012a, p. 28), lá mesmo onde, paradoxalmente, o humano é compelido a ajustar-se às relações técnicas que lhe tolhem as possibilidades mais genuínas de uma existência livre.

Essa a razão crucial pela qual, no entender de Heidegger, reivindicar uma ética para o universo da técnica pode significar tão-somente seguir tratando do problema da técnica como algo técnico, porque, afinal, a técnica costuma figurar apenas como um negócio do homem, quando o fundamental mesmo - diz ele (1999, p. 179) - é que "prestemos atenção ao apelo cujo alvo em nossa época não é apenas o homem, mas tudo o que é natureza e história, sob o ponto de vista de seu ser". Gestell-sugeriu- é o que nomeia, nessa apelação, o processo de provocação que confronta o homem e o ser, tendo este caído em seu mais completo esquecimento enquanto essência mesma da técnica.

Acima de tudo, a Heidegger, nesse tocante, interessava um gênero novo do pensamento, que não se ocupasse mais, primordialmente, com a ordenação dos fenômenos num sistema unilateral, uniforme, padronizado, mas que tornasse possível e fosse mesmo uma condição nova de possibilidade para uma reflexão atuante, a contrapelo do pensamento metafísico, manipulador e calculante, responsável pela ocultação e esquecimento do ser. Ein besinnendes Denken foi como Heidegger chamou a esse pensamento alternativo que pensa, que atribui um significado $(C f$. HODGE, 1995, p. 47).

\section{Metafísica do Humanismo Tecnocientífico}

Sob o imperativo do cálculo assegurador do fazer sem meta que é inerente à-vontade de poder da técnica, entende-se o porquê de usualmente associar-se o estado de coisas representado pela instrumentalização -e o consequente apequenamento do homem-a uma crise do humanismo produzida, supostamente, "de fora" e não, como é o caso, a partir "de dentro" do próprio projeto humanista de racionalização generalizada da vida. Presume-se, em geral, que a conversão do humano em recurso decorreu, sobretudo, da desintegração do fundamento metafísico que lhe conferia uma espécie de direito, uma razão de ser. Com o desfecho da metafísica, enquanto sistema teórico-especulativo-doutrinário, teria também chegado ao fim seu sistema de verdade garantidor do papel do homem como referência organizadora da totalidade.

Nas palavras de Nietzsche (2008, p.32), "surge então a última forma de niilismo, que inclui em si a descrença em um mundo metafísico -que interdita a crença em um mundo verdadeiro". É sob esse influxo do esgotamento das possibilidades intrínsecas dos princípios e postulados da metafísica, realizada como redução objetificadora do ser na era da técnica, que vicejam, por fim, os metarrelatos substitutivos da unidade do processo histórico oferecido pala metafísica.

Ora, desde sempre a tradição humanista e a metafísica se conjugaram. Em seu significado essencial, o humanismo pertence ao cerne da metafísica e não passa mesmo de uma exortação à realização, através da ciência e da técnica, da imagem do mundo que progride como obra de um vasto sistema de causas e efeitos. Assim, não procede que o caráter distópico do humanismo radique na desvirtuação dos valores pretensamente humanísticos da metafísica, como se ela mesma já não consistisse numa expropriação do humano em sua verdade do ser, já não consistisse numa servidão do homem para o fazer da técnica -a despeito da centralidade que ela mesma reivindica para o humano como princípio de toda realidade.

Por trás da representação do humano como fundamento da entidade dos entes, o que efetivamente tem lugar é o "fazer violento" da animalitas do homem que é invocado pela metafísica a assumir o controle e domínio do mundo. Não há, pois, que se associar a distopia do humanismo a um eventual descaminho desumanizante da técnica, dado que, como tal, a 
tecnificação do mundo realiza-se como concretização da ideia de que o homem, em sua essência universal compreendida a partir de seu desenvolvimento racional, "pensa o ser das coisas como algo que depende dele próprio e que a ele se reduz" (COCCO, 2006, p.39).

Vattimo (1996, pp.28-29), a esse respeito, foi taxativo: “o fato de a técnica se apresentar como uma ameaça para a metafísica e para o humanismo é apenas uma aparência, derivada de que, na técnica, desvendam-se as características próprias da metafísica e do humanismo...". Então, a ideia convencional segundo a qual o humanismo representa um antídoto à desumanização da técnica e que condiz com valores alternativos aos do tecnificação do mundo não se sustenta. Propriamente falando, o humanismo é aquele traço da metafísica que funda o homem como subjectum, como grund da realidade, isto é, como substrato de toda objetificação. Conforme Heidegger deixou claro, a crise do humanismo se acha estreitamente ligada à era da tecnificação enquanto metafísica consumada, e ao que nela remanesceu como o impensado da diferença entre ente e ser, que, em última instância, obstruiu a formulação da pergunta acerca da verdade do homem como pertencente à verdade do ser.

De um modo dramático, o sujeito que tudo objetifica acaba ele mesmo, et pour cause, sujeitado à própria objetificação da realidade, isto é, acaba reduzido a uma função reificadora de sua existência, a uma coisa entre coisas no universo técnico do produzir pelo produzir. Em vista disso, nada, com efeito, se pode resguardar ou pôr-se "a salvo" do furor da técnica. O "nada" em questão vale tanto para a "natureza" administrada, manipulada e explorada, quanto para o humano tornado recurso (capital humano) igualmente administrado, manipulado e explorado já como traço insofismável do abandono do ser.

Participar desse empreendimento da razão e de suas conquistas lastreadas na concepção redutora do ser a mera instrumentalidade foi sempre entendido como o verdadeiro alicerce do progresso humano. O humanismo, por conseguinte, tem a ver com essa maquinação asseguradora do domínio técnico total do ente em meio à apreensão do sentido do ser como experiência, em nossa época, que faz dele algo racionalmente objetivável e calculável. Do contrário, entende-se, não se poderia falar em realidade, ao menos não da realidade que emerge do cunho operativo da técnica.

Logo, procurar resgatar, em nome do próprio humanismo objetificante, qualquer coisa como a autenticidade perdida do sujeito em sua liberdade e dignidade soa, no mínimo, estranho e paradoxal. Simplesmente não há uma tal coisa como uma humanitas do homem guardada no interior do projeto metafísico de realização técnica do mundo. $O$ que se concretizou, como decorrência do fomento à manipulação planetária do mundo como objeto para um sujeito -e, portanto, como conquista de uma subjetividade autorreferida-, foi obra do humanismo do homem da provocação incondicionada da natureza capturada como fundo de reserva.

Em sua condição radical de antropologia do ser em poder do sujeito, o humanismo não deixa o ser das coisas ser, como enredo que é do modo de produção técnico das coisas, isto é, enquanto regência do modo unilateral e infringente de provocar o aparecimento das coisas. Posicionado, assim, sob a cunha da razão calculadora e instrumentalista da técnica, ao fim e ao cabo o humanismo se volta contra a própria "humanidade do homem" em sua abertura para o ser, para o autodeterminado de suas possibilidades. É esse o elemento predisponente da dimensão distópica do humanismo experimentada como desumanização geral do homem imerso no universo da técnica.

Do que precede, então, vê-se que não cabe pretender cingir a crise do humanismo $(C f$. HEIDEGGER, 2006) a um suposto o caso da metafísica. Nem no sentido de superada como culminância na técnica, nem como culminação em si da técnica que ensejaria, por sua vez, a emergência de um pensar, à la Habermas, pós-metafísico, de extração, consequentemente, já pós-humanista, porque, com efeito, não mais enredado numa concepção estática da essência do 
humano, a partir de cujo fundamento metafísico ficava-lhe outorgada uma valoração distinguida como liberdade e dignidade do homem -valores esses que o sistema de mobilização total da técnica debilita como operatio de uma forma de racionalidade custodiada pelo humanismo que Heidegger internou na metafísica. Internou porque viu no humanismo a identificação metafísica do ser como objeto submetido ao poder do homem, isto é, o ser como manifestação plenipotenciária da vontade de poder que leva ao paroxismo a investidura do homem da técnica no papel de sujeito criador de mundos. Nesse sentido,

se vale a análise heideggeriana do nexo entre metafísica, humanismo e técnica, o sujeito que nos era proposto defender da desumanização técnica era, precisamente ele, a raiz dessa desumanização, já que a subjetividade que se define doravante apenas como o sujeito do objeto é pura função do mundo da objetividade, tendendo, ao contrário, irrefreavelmente, a também se tornar objeto de manipulação (VATTIMO, 1996, p.35).

Mas do mesmo modo que "o homem [só] conserva seu lugar como centro da realidade (concepção humanista) em virtude de uma referência a um fundamento metafísico que o afirma nesse posto" (SÁNCHEZ MECA, 2010, p.197) e faz de sua essência algo idêntico à metafísica, também a essência da tecnologia moderna, que é a tecnologia das máquinas, é idêntica à essência do pensamento metafísico ( $C f$. HEIDEGGER, 2012a). Isso porque a essência da técnica não se confunde com algo instrumental, por mais intuitiva e tentadora que seja a ideia de fazê-la passar-se por médium coadjuvante da atividade humana. Tampouco constitui a técnica, para Heidegger, mera aplicação da ciência, senão que a ciência é que é já, ela mesma, um ordenamento da mentalidade tecnocientífica objetivadora do processamento técnico do real, isto é, um âmbito objetual do factível na representação do pensamento ocidental como um modo de ser no mundo.

Na modernidade tecnocientífica, a técnica é, acima de tudo, um modo de desvelar os entes como reserva ou fundo disponível (Bestand). Aquilo que do ser não se dá nem se mostra por si a técnica patenteia à sua maneira no domínio do cálculo que permite absolutizar a verdade do ente e assim administrar sua presença como disponibilidade permanente. Nesse sentido, é um modo de desabrigar a natureza de suas particularidades, porque a trata como coisa, como matéria-prima, apenas, e não como um mundo que emerge em si mesmo. Como tal, compreendese já como uma forma de saber (das conexões meios fins) que - através do pensar calculante da episteme tecnocientífica moderna- projeta e produz a "realidade" ao conduzir o ente do apreendido (em sua dimensão metafísica do desvelado em sua essência a partir de categorias e conceitos) ao administrado enquanto domínio, que se torna unilateral, da manifestação de sua totalidade.

Como episteme tecnicamente agenciada para essa representação processadora do real, o pensamento científico-tecnológico tem no determinante metafísico da técnica sua anterioridade constitutiva. Assim, e ao contrário do que é amplamente aceito, a técnica não é mera ciência aplicada e nem seu consequente, mas, a bem da verdade, seu antecedente lógico, como sua essência enquanto fundamento metafísico. No dizer de Galimberti (2006, p.347), "a potência técnica que desvela a ciência destina a ciência à ampliação da potência" [da técnica] em sua condição de vontade que se quer a si mesma, como força autônoma que se dá a si própria $a$ norma que põe tudo a funcionar do mesmo modo, em todos os lugares, concatenadamente.

Ocorre que a essência da técnica, como mecanismo ou dispositivo (Gestell) autorreferido, manifesta-se como imposição ou composição justamente porque conduz, implica, provoca o aparecimento dos entes. Com a "natureza" tendo sido levada à ordenação como fundo objetivávelda ciência moderna, o projeto metafísico da calculabilidade do real amadurece na técnica contemporânea. Sem isso, evidentemente, não se teria podido chegar à realidade do 
mundo da técnica e de sua maneira de posicionar os entes como reserva ou estoque, para o que vale realçar- o método da ciência moderna de dominação tecnológica da natureza foi decisivo, no tocante à materialização de uma forma prévia de apreensão metafísica do real, que é com a qual se lança ao trabalho de "fazer do ser um objeto racional, calculável e operacionalmente manipulável" (SÁNCHEZ MECA, 2010, p.181).

Em suma, a ciência moderna surge e se desenvolve apoiada no mesmo substrato metafísico do pensamento calculante da técnica que a estruturou como seu braço operacional da objetidade. Nas palavras de Heidegger (2006, p.114), "só há ciência como pesquisa a partir do momento em que a verdade se torna certeza sobre a representação", quer dizer, a partir do momento em que se faculta à ciência executar sua trajetória ancorada no pressuposto metafísico da objetivação da realidade como sua forma primordial de trato. E no sentido de tratar-observa Heidegger (2012c, p. 48)

a ciência é uma elaboração do real terrivelmente intervencionista. Precisamente com este tipo de elaboração, a ciência corresponde a um traço básico do próprio real. O real é o vigente que se ex-põe e des-taca em sua vigência. Este destaque se mostra, entretanto, na Idade Moderna, de tal maneira que estabelece e consolida a sua vigência, transformando-a em objetidade. A ciência corresponde a esta regência objetivada do real à medida que, por sua atividade de teoria, ex-plora e dis-põe do real na objetidade. A ciência põe o real. E o dis-põe a pro-por-se num conjunto de operações e processamentos, isto é, numa sequência de causas aduzidas que se podem prever. Desta maneira, o real pode ser previsível e tornar-se perseguido em suas consequências.

\section{Considerações finais}

A disseminação da mundividência científica moderna solapou a crença na certeza da revelação como expressão da verdade, e desse modo pavimentou o caminho para o controle do mundo pelo sujeito que, tendo usurpado para si o engenho divino, desponta como regente da representação do mundo reduzido a cálculo. $O$ humanismo tem a ver com a realização dessa ideia segundo a qual a natureza é compelida a se apresentar como objeto para o homem, ou seja, o humanismo corresponde, à outrance, à humanização da natureza conduzida pelo homem que a modernidade da técnica transformou em fulcro de todas as coisas.

Em sua interpelação da técnica como o acontecimento histórico-ontológico da metafísica, Heidegger aludiu ao ordenamento provocador que nela vige e que desafia o homem a desvelar o ser dos entes como "disponibilização permanente" (Bestand), por meio do processo imparável de geração de objetos sem valor intrínseco para a existência humana. Mobilizado como recurso nessa maquinação da técnica moderna, o homem, enfim, chega ao nada, tendo ele mesmo se tornado, de acordo com Heidegger, uma "besta de trabalho", um "funcionário da técnica", um "homem-sujeito" inteiramente dominado pela materialidade da mundialização tecnológica. Compelido a ser só trabalho (fabricar, produzir, transformar e consumir), ele interioriza, dessa forma, a essência da técnica como naturalização de umas práxis que o predispõe a uma conduta calculista e maximizadora do mundo ambiente reduzido - no humanismo da modernidade-, a meio racionalizado de exploração da natureza dominada.

Quer dizer, o dominante foi dominado, o objetivante, objetivado; o conquistador, conquistado pela sua conquista. Como um todo, o processo técnico lhe escapa ao controle. Na ausência de um sentido predeterminado para seus afazeres, o mestre e possuidor da natureza converte-se em voluntário da "vontade de vontade", isto é, em operador coisificado da produtibilidade infringente que é o produzir pelo produzir remetido ao "querer da vontade" que é "nulidade do nada". 


\section{Referências}

ARENDT, Hannah. Eichmann in Jerusalem: a reporton the banality of evil. New York: The Viking Press, 1964.

ARENDT, Hannah. A vida do espirito (Vol. I). Trad. Antônio Abranches. 4ed. Rio de Janeiro: Relume Dumará, 2000.

BORGES-DUARTE, I. Arte e técnica em Heidegger. Lisboa: Documenta, 2014.

COCCO, Ricardo. “A questão da técnica em Martin Heidegger”. Controvérsia-v.2, n.1, p. 34-54 (jan-jun 2006).

GALIMBERTI, Umberto. Psiche e techné: o homem na idade da técnica. Trad. José Maria de Almeida. São Paulo: Paulus, 2006.

HABERMAS, Jürgen. Pensamento pós-metafísico: estudos filosóficos. Trad. Flávio Breno Siebeneichler. Rio de Janeiro: Tempo Brasileiro, 1990.

HABERMAS, Jürgen. $O$ discurso filosófico da modernidade: doze lições. Trad. Luiz S. Repa \& Rodnei Nascimento. São Paulo: Martins Fontes, 2000.

HABERMAS, Jürgen. Ciencia y técnica como "ideologia". Trad. Manuel Jiménez Redondo. Madrid: Tecnos, 1986.

HEIDEGGER, Martin. "O princípio da identidade". Trad. Ernildo Stein. In: Conferências e Ensaios Filosóficos. (Coleção Os Pensadores). São Paulo: Nova Cultural, 1999.

HEIDEGGER, Martin. Carta sobre el humanismo. Trad. Helena Cortés y Arturo Leyte. 4ed. Madrid: Alianza Editorial, 2006.

HEIDEGGER, Martin. “A questão da técnica". Trad. Emmanuel Carneiro Leão. In: Ensaios e Conferências. Petrópolis: Vozes, 2012a.

HEIDEGGER, Martin. "A superação da metafísica". Trad. Marcia Sá Cavalcante Schuback. In: Ensaios e Conferências. Petrópolis: Vozes, 2012b.

HEIDEGGER, Martin. "Ciência e pensamento do sentido". Trad. Emmanuel Carneiro Leão. In: Ensaios e Conferências. Petrópolis: Vozes, 2012c.

HEIDEGGER, Martin. "O que quer dizer pensar". Trad. Gilvan Fogel. In: Ensaios e Conferências. Petrópolis: Vozes, 2012d.

HODGE, Joanna. Heidegger and ethics. London \& New York: Routledge, 1995.

LEOPOLDO E SILVA, F. "Martin Heidegger e a técnica". Scientiae Studia (v. 5, n. 3, pp. 36974), São Paulo, 2007.

NIETZSCHE, Friedrich. $O$ anticristo e ditirambos de Dionísio. Trad. Paulo César de Souza. São Paulo: Companhia das Letras, 2007.

NIETZSCHE, Friedrich. A vontade de poder. Trad. Marcos. S. P Fernandes \& Francisco J. Dias de Moraes. Rio de Janeiro: Contraponto, 2008.

NIETZSCHE, Friedrich. Assim falou Zaratustra. Trad. Paulo César de Souza. São Paulo: Companhia das Letras, 2011.

PICOTTI, Dina. Heidegger: una introducción. Buenos Aires: Quadrata, 2010.

SÁNCHEZ MECA, Diego. El nihilismo. Madrid: Editorial Sinteses, 2010.

VATTIMO, Gianni. As aventuras da diferença. Trad. José E. Rodil. Lisboa: Edições 70, 1980.

VATTIMO, Gianni. O Fim da modernidade: niilismo e hermenêutica na cultura pós-moderna. Trad. Eduardo Brandão. São Paulo: Martins fontes, 1996.

Autor(a) para correspondência: Antônio José Nascimento, Cidade Universitária Prof. José Aloísio de Campos, Jardim Rosa Elze, 49100000, São Cristóvão - SE, Brasil. E-mail: ajntoinho@outlook.com 